\title{
Entre la negación histérica y la adaptación. La política pública del Ministerio de Seguridad de la Provincia de Santa Fe en relación al narcomenudeo a partir del caso Los Monos. Rosario, 2012-2015
}

Between hysterical denial and adaptation. The public policy of the security department of Santa Fe province in relation to local drug dealing since Los

Monos event

Javier Gañán ${ }^{1}$

\section{Resumen}

En este artículo se analizan algunos elementos que condicionaron la formulación de la política pública del Ministerio de Seguridad de la Provincia de Santa Fe en relación al fenómeno del narcomenudeo en Rosario entre 2012 y 2015, tomando como caso de estudio al clan "Los Monos". Se sostiene que la agenda gubernamental incorporó la temática en términos de "combate al narcotráfico" sirviéndose de la versión predominante en la agenda pública. La construcción mediática alrededor de la "cuestión narco" presentaba un enemigo, un otro con facilidad de ser caracterizado como amenazante frente a la opinión pública. La problematización que el Ministerio de Seguridad realizó se sirvió de aquella caracterización mediática para intentar salir de la encerrona de la coyuntura crítica enmarcada con un aumento sostenido de la tasa de homicidios dolosos.

Palabras clave: Narcomenudeo, Los Monos, Políticas de Seguridad, Rosario

\section{Abstract}

This article analyzes the elements that conditioned the formulation of public policy of the Security departament form Santa Fe in relation to the local drug phenomenon in Rosario between 2012 and 2015, taking as study case "Los Monos". It is argued that the

Recibido: 18 de julio de 2019 Aceptado: 30 de noviembre de 2019 Publicado: 20 de diciembre de 2019

${ }^{1}$ Licenciado en Ciencia Política (UNR). Correo electrónico: javiganan@yahoo.com.ar 
government agenda incorporated the theme in terms of "combating drug trafficking" using the predominant version of the public agenda. The media construction around the "narco issue" presented an enemy, another easily characterized as threatening in the face of public opinion. The problematization that the Ministry of Security made used that media characterization to try to get out of the trap of the critical juncture framed with a sustained increase in the rate of intentional homicides.

Keywords: drug trafficking, Los Monos, Security politics, Rosario

\section{Introducción}

En el presente trabajo nos proponemos identificar y analizar algunos elementos que condicionaron la formulación de la política pública del Ministerio de Seguridad (en adelante, MS) de la Provincia de Santa Fe en relación al fenómeno del narcomenudeo en Rosario entre 2012 y 2015, tomando como caso de estudio a "Los Monos", grupo de la ciudad liderado por miembros de la familia Cantero.

En el período delimitado, la agenda gubernamental del MS se vio atravesada por una serie de cuestiones, a saber: elevadas tasas de homicidios, casos de corrupción policial extendida a las cúpulas de la institución, crisis en materia de seguridad, aumento de la inseguridad urbana, etc., algunas de ellas generadas por el propio ministerio. Estas ingresaron a la agenda pública como ligadas al narcotráfico e influyeron en la incorporación del tema en la agenda de gobierno. Nos interrogamos entones ¿Cómo problematizaron e intervinieron sobre la problemática del narcomenudeo las áreas competentes del MS de la Provincia de Santa Fe? ¿Qué elementos condicionaron la formulación de políticas públicas del MS en relación al narcomenudeo?

El narcotráfico ${ }^{2}$ se presenta como una temática que parece interpelar al conjunto de la sociedad. Adjetivado habitualmente como "flagelo", suele ser señalado como causal de un conjunto de fenómenos tales como la creciente tasa de homicidios, el delito juvenil urbano, entre otros. Sin embargo, no existe constatación que lo ubique como explicación última de toda violencia o fenómeno de inseguridad urbana.

\footnotetext{
${ }^{2}$ En un primer momento utilizaremos este término debido a que es el que mayormente se emplea. Luego problematizaremos el concepto a fines de dar cuenta del fenómeno de la venta al menudeo de drogas ilícitas en la ciudad de Rosario.
} 
El denominado "avance del narcotráfico" en la ciudad de Rosario fue, adquiriendo cada vez mayor relevancia como problema público a comienzos del año 2012, a partir de una serie de hechos violentos, entre los que destacan el homicidio de tres jóvenes militantes en un barrio de la zona sur rosarina y una seguidilla de muertos (algunos en zonas céntricas de la ciudad) a veces en el marco de enfrentamientos entre bandas dedicadas al narcomenudeo. Unos meses después (octubre de 2012), la detención del jefe de la PSF -acusado de proteger a Carlos Ascaíni, un narcotraficante del sur de la provincia de Santa Fe- consolidó cierto imaginario social en el que Rosario era señalada como germen del crecimiento del narcotráfico en el país.

Tanto desde medios masivos de comunicación cómo desde diversos sectores políticos, habitualmente se hace alusión a los acontecimientos de bandas delictivas dedicadas a la comercialización de drogas ilegales -marihuana y cocaína principalmente- que actúan en la ciudad de Rosario. Estas voces suelen comparar el fenómeno con un relato inverosímil de la realidad colombiana o mejicana ${ }^{3}$ en el que los "narcos" aparecen como grupos con un creciente grado de poder y en condiciones de disputar el control territorial al Estado, tanto en estamentos municipales, provinciales, como también nacional.

\section{Metodología}

El trabajo de investigación ${ }^{4}$ sobre el que está basado el presente artículo constó de diversas entrevistas ${ }^{5}$ a actores fundamentales del Poder Judicial de la Provincia de Santa Fe, Poder Judicial de la Nación, periodistas de "policiales" y abogados de causas vinculadas a "narcomenudeo". Todos ellos interiorizados en la denominada "Mega causa Los Monos”.

Centraremos la atención en el caso del clan "Los Monos", debido a su trascendencia mediática y política, desde donde analizaremos los patrones que

\footnotetext{
${ }^{3}$ El informe elaborado por el exitoso programa televisivo PPT (Periodismo Para Todos) emitido el 10 de Noviembre de 2013 da cuenta de las representaciones que se construyeron respecto a la ciudad de Rosario abonando a un relato que es una muestra cabal de dos preconceptos que se hicieron hegemónicos respecto al fenómeno del narcotráfico en la ciudad: la comparación constante con ciudades como Medellín (Colombia) o Ciudad Juárez (Méjico) por un lado y la vinculación causal entre homicidios y narcotráfico por otro. Disponible en línea: http://tn.com.ar/politica/narcypop-rosario-la-medellin-argentina_421306.

${ }^{4}$ Tesina de grado Licenciatura en Ciencia Política y Relaciones Internacionales, Facultad de Ciencia Política y Relaciones Internacionales, Universidad Nacional de Rosario. Gañán, Javier (2017), "Entre la negación y la adaptación. La política pública del Ministerio de Seguridad de la Provincia de Santa Fe en relación al narcomenudeo a partir del caso Los Monos. Rosario, 2012- 2015”, 2017,

${ }^{5}$ Para el presente artículo se optó por no hacer nombres propios y preservar la identidad de los entrevistados.
} 
delimitaron y condicionaron la formulación de una política pública por parte del MS en materia de comercialización de drogas ilícitas entre los años 2012 y 2015.

En cuanto a las técnicas empleadas para producir y recolectar datos, considerando la vacancia de investigaciones disponibles sobre la temática aquí abordada, se optó en primer lugar por realizar entrevistas en profundidad. Los entrevistados son informantes claves que mediante sus reconstrucciones discursivas del fenómeno, darán una pauta que permita componer cómo fue problematizando el MS el fenómeno del narcomenudeo y cómo fue influyendo en el devenir de la cuestión.

En el caso del análisis del desenvolvimiento del MS y de la caracterización que dicha agencia tuvo del fenómeno narcomenudeo en el período estudiado, se suplió la ausencia de entrevistas con el relevamiento de notas y testimonios recabadas en diferentes medios de comunicación; y análisis del denominado "Plan de Seguridad Democrática ${ }^{6 ”}$, de modo que permitan analizar el posicionamiento público de los protagonistas, la problematización que dicha agencia realizó sobre la cuestión y las principales intervenciones.

\section{Precisando conceptos}

¿Qué es el narcomenudeo?

En contadas ocasiones, el narcotráfico suele ser considerado como un entramado de actores, con un devenir que se desarrolla y se inserta en una realidad socio-económica que lo contiene. Los paraísos fiscales ${ }^{7}$ y su falta de transparencia respecto del origen de los capitales dan cuenta de ello. La última fase de cualquier ciclo económico delictivo -el "lavado" de los beneficios acumulados- debería reenviarnos al sistema bancario y financiero internacional (Ruggiero, 2005).

A nuestro parecer es importante resaltar la heterogeneidad de actores que pueden encontrarse al interior del narcotráfico. Para dar cuenta del aspecto que aquí nos interesa, creemos pertinente hacer referencia al concepto de narcomenudeo (Vilalta Perdomo, 2008; Zamudio Angles, 2013; Garzón, 2015). Con este término nos referimos a la venta al por menor de drogas ilícitas con destino exclusivo al mercado

\footnotetext{
${ }^{6}$ El Plan de Seguridad Democrática fue elaborado por el Poder Ejecutivo de la Provincia en octubre de 2012. Contemplaba un incremento de recursos económicos y humanos destinados a seguridad, durante 18 meses. A su vez contemplaba una reestructuración de la fuerza policial, sobre ello volveremos en los capítulos siguientes.

7 "El término, aun siendo polémico, sirve para designar a los países y territorios con escasa o nula tributación para las operaciones financieras, que aparecen relacionados periódicamente con hechos delictivos y escándalos financieros, como los de Enron, Gescartera, Parmalat y muchos otros, que trascienden a los demás Estados, cuyas economías dañan, facilitando la evasión fiscal y la delincuencia financiera de todo tipo globalizada" (Hernadez Vigueras, 2006:14).
} 
local o nacional, diferenciándolo de narcotráfico, donde se manejan mayores volúmenes de dinero, una organización mucho mas estructurada ${ }^{8}$, articulada de manera transnacional y con capacidad de "blanquear" ${ }^{\prime 9}$ dinero mediante las estructuras formales en entidades financieras internacionales. Como veremos, el caso de "Los Monos" se clasifica como lo que aquí se refiere como narcomenudeo.

Igual de necesaria que la distinción entre narcotráfico y narcomenudeo nos parece la distinción al interior de este último entre quienes dirigen la actividad y quienes se insertan en ella motivados por la necesidad de algún ingreso, en algunos casos como recurso de subsistencia. Existen al interior del narcomenudeo empresarios -que invierten su capital y corren riesgos financieros- y empleados -que, en distintas modalidades de subcontratación, cumplen ordenes sin invertir capital (Zaitch, 2009) -. Esta distinción resulta de suma importancia a la hora de analizar el caso en cuestión y el modo de intervención de las agencias estatales, penales y fuerzas de seguridad.

\section{Políticas de Seguridad y "narcomenudeo"}

La criminología crítica y la sociología brindan herramientas conceptuales a fines de comprender cómo a partir de los cambios sociales que trajo consigo la modernidad tardía $a^{10}$, el delito y el castigo se han transformado en cuestiones electorales. Garland y Young entre otros analizan esta cuestión asignándole a los partidos políticos un importante rol en tanto "comenzaron a competir para ser reconocidos como 'duros' con el delito, preocupados por la seguridad pública y capaces de restablecer la moralidad, el orden y la disciplina frente a los corrosivos cambios de la modernidad tardía" (Garland, 2005:223).

Desde esta óptica se sostiene que las políticas en materia de seguridad son ambivalentes y contradictorias, e implican un dilema a partir de la normalización de las altas tasas de delito y las limitaciones reconocidas de la justicia penal estatal (Garland,

\footnotetext{
${ }^{8}$ Al respecto, como fuera adelantado, Cecilia González señala un proceso de "Macdonalización” del narcotráfico en Méjico, donde las personas involucradas se insertan en una compleja división de tareas coordinadas al punto tal que "es difícil saber quién es el jefe. Tercerizan cada parte de la operación. Sobre todo, los que están en los rangos más bajos, están cometiendo un delito pero no saben para quién están trabajando. No son "lugartenientes de" (González, 2013:11).

${ }^{9}$ Operación que consiste en hacer que los fondos o activos obtenidos a través de actividades ilícitas aparezcan como el fruto de actividades legales y circulen sin problema en el sistema financiero.

${ }^{10} \mathrm{El}$ termino modernidad tardía puede esclarecerse poniéndolo en relación con lo que autores del pensamiento posfundacional como Oliver Marchart o Claude Lefort han marcado como la disolución de los marcadores de certidumbre propios de la modernidad clásica. Esta postura sostiene que asistimos a una indeterminación atravesada por la caída de los principios trascendentales de certeza propios de la modernidad clásica. En este sentido el Estado no aparece como único ordenador de la vida de los ciudadanos.
} 
2005). Aquella ambivalencia señalada radica principalmente entre la aceptación, por un lado, de que las políticas en relación al control del delito no logran efectos debido a la erosión del mito del estado soberano. Y la necesidad de mostrar a la ciudadanía resultados en el plano de la seguridad pública. Garland advierte "el signo de nuestro tiempo no es la 'punitividad' sino es la ambivalencia. Se oscila erráticamente entre la "adaptación" y la "negación", entre las tentativas de enfrentar la situación y las de hacerlas desaparecer mágicamente" (Garland, 2005:97). Reitera en su libro que "mientras la maquinaria administrativa del Estado ha diseñado estrategias, adaptándose a sus limitaciones y ajustándolas a las transformaciones del contexto social, la maquinaria política estatal se ha entregado repetidamente a una forma de evasión y negación que es prácticamente histérica, en el sentido clínico del término. (Garland, 2005:222). Sobre ello volveremos a la hora de analizar las políticas públicas del MS en relación al narcomenudeo.

\section{“Los Monos" en la ley de la selva}

Si bien desde tiempo atrás el apellido Cantero frecuentaba las páginas de la sección "Policiales" de los principales diarios de la ciudad de Rosario, fue a partir del asesinato de Claudio "Pájaro" Cantero ${ }^{11}$, en mayo de 2013, que "Los Monos" pasaron a ser sinónimo de la denominación, del significante "narco", alcanzando fama nacional ${ }^{12}$.

Pocos días después de este homicidio, el gobierno provincial se hacía eco de la caracterización mediática. Exponiendo objetos incautados a "Los Monos", el entonces Gobernador Bonfatti aparecía junto al juez Juan Carlos Vienna demostrando que se había logrado un gran golpe al narcotráfico ${ }^{13}$. Allí se inauguraba una política neurálgica de la gestión de Raúl Lamberto ${ }^{14}$ al frente del Ministerio de Seguridad provincial: el "combate al narcotráfico" pasaría a ser un nuevo eje de la política de seguridad provincial.

Según logramos reconstruir a partir de los testimonios recabados en las entrevistas en profundidad y en las noticias periodísticas consultadas, desde 2003 -

\footnotetext{
${ }^{11}$ Claudio Cantero, apodado "Pájaro", era señalado, al momento de su asesinato, como líder de la banda "Los Monos". La Capital, 27/05/13. Disponible en: http://www.lacapital.com.ar/policiales/asesinaron-seis-balazos-alpajaro-cantero-lider-los-monos-n419297.html.

12 "Droga y crímenes mafiosos: la historia de 'Los Monos ', la banda que aterroriza Rosario". Clarín, 23/02/14. Disponible en http://www.clarin.com/policiales/historia-Monos-banda-aterroriza-Rosario_0_1090091141.html. 13 Imágenes del operativo conjunto disponibles en http://www.lacapital.com.ar/policiales/un-fiscal-se-niegafirmar-el-juicio-abreviado-los-monos-y-ofrece-su-renuncia-n491908.html. Fecha de consulta: 02/02/17.

14 "Raúl Lamberto asumió como nuevo Ministro de Seguridad". El Ciudadano, 11/06/12. Disponible en: http://www.elciudadanoweb.com/raul-lamberto-asumio-como-nuevo-ministro-de-seguridad/.
} 
luego del fallecimiento de Juan Carlos "el Mono Miguel" Fernández ${ }^{15}$-, Máximo Ariel "El Viejo" Cantero lideraba la banda en el barrio Las Flores de la zona sur de Rosario, un territorio periférico de la ciudad, dividido entre Las Flores Sur y Las Flores Este, perteneciente al Distrito Sudoeste de la Municipalidad de Rosario. Las Flores es uno de los barrios cuya población está expuesta a altos déficits habitacionales y económicos. Las marcas de la desindustrialización y las pérdidas de fuentes laborales de fines de siglo XX fueron conformando a la informalidad como "rebusque" de ingresos por parte de sus habitantes. Al mismo tiempo, sus vecinos conviven con la estigmatización de que Las Flores sea catalogado como barrio peligroso y violento ${ }^{16}$.

Por esa época, "Los Monos" ya eran una banda organizada y consolidada en la zona ${ }^{17}$. Los hijos de Máximo, Claudio "Pájaro" Cantero y Ariel "Guille" Cantero, junto a Alexis "Monchi" Machuca (un joven adoptado como hijo propio por Celestina "la Cele" Contreras, mujer de "El Viejo" Cantero) eran quienes lo secundaban en el clan. Respecto a los orígenes de la banda, un periodista de policiales [P1] entrevistado relata que "Los Monos 'surgieron inicialmente en Las Flores Sur a partir de un clan familiar conocido como 'Los Fernández '. De manera paralela en Las Flores Este, hay otro clan, que es el clan Cantero. Te estoy hablando aproximadamente 30, 35 años atrás, que coinciden en casarse Ariel Cantero y Juan Carlos Fernández, conocido como "el Mono Miguel" con dos hermanas, las hermanas Contreras."

A continuación, analizaremos -valiéndonos de las entrevistas realizadas y de fuentes secundarias- cómo estaba compuesto en la ciudad de Rosario el conglomerado de actores del narcomenudeo en el período aquí delimitado y qué lugar ocupaban "Los Monos" en el mismo. Eventon considera que "cuatro o cinco grandes grupos controlan la distribución de drogas ilícitas en Rosario" (Eventon, 2013:2), lo cual pudo corroborarse a través de las entrevistas realizadas. En palabras del fiscal general de una de las causas judiciales en relación al caso de estudio se afirma: "Los Monos 'eran uno de los cuatro o cinco grupos importantes que operaban en la comercialización de drogas acá en la ciudad de Rosario. A la ciudad te diría que la podríamos haber dividido en una especie de damero: la zona sudeste prácticamente en manos de ellos. La zona sudoeste manejada por otro grupo [no aclara] que ahora también cayó detenido. La

\footnotetext{
${ }^{15}$ Líder original de la banda "Los Monos" hasta el año 2000, cuando comenzó a compartir el liderazgo con su concuñado, Máximo Ariel Cantero.

16 "Cómo es vivir en Las Flores Sur, un barrio rosarino cargado de estigmas". La Capital, 27/07/08. Disponible en: http://www.lacapital.com.ar/la-ciudad/coacutemo-es-vivir-las-flores-sur-un-barrio-rosarino-cargado-estigmasn289944.html. Fecha de consulta: 10/02/16.

17 "Los Monos se quedaron sin su líder". La Capital, 27/10/04. Disponible en: http://archivo.lacapital.com.ar/2004/10/27/policiales/noticia_144678.shtml. Fecha de consulta: 14/03/16.
} 
zona noreste, está todavía detenido en San Isidro el que manejaba aquel sector [Esteban Alvarado ${ }^{18}$ ], que tenía doble negocio: manejaba autos robados y droga. Después estaba Luis Medina, hoy muerto, que manejaba otro sector. O sea, eran cuatro o cinco grupos fuertes que manejaban la droga"19.

Creemos pertinente citar otro fragmento de la entrevista con un periodista de policiales de la ciudad [P1]: "Los Monos 'fueron consiguiendo -a través de la protección policial- hegemonizar ese negocio; no el de la droga en sí mismo, sino el de cobrarle a todo el mundo peaje ${ }^{20}$. Hasta un par de años antes de caer, lo habían logrado hasta [Avenida] Pellegrini, y más allá de la división de la ciudad donde el noroeste le correspondía a Medina y Alvarado y el sur a ellos. No es descabellado pensar que Medina y Alvarado también pagaban por protección. El único que no pagaba por protección era Zacarías ${ }^{21}$, que proveía un par de bunkers en zona Sur, pero no era lo que se dice un 'dueño de territorio ', sino que estaba especializado en la importación de alita peruan $a^{22}$ y pasta base para cocinar la cocaína acá. En todo este entramado, lo único que surge por afuera y que podría vincularse con algún negocio de exportación podría ser el nombre propio de Medina. Si hablamos de exportación estamos hablando de otra cosa, hablamos de la causa judicial "Peras blancas" ${ }^{23}$, "Carbón blanco" ${ }^{24}$, pero en realidad no está acreditado que 'Los Monos 'tengan que ver, o hayan tenido que ver con sectores de la exportación" 25 .

Las descripciones y caracterizaciones que los entrevistados realizan de "Los Monos" son interesantes para relativizar uno de los preconceptos mayormente aludidos frente a la "situación del narcotráfico" en la ciudad; aquel que señala que en Rosario se está asistiendo a una situación que tiende a asemejarse a la de Ciudad Juárez en Méjico o Medellín en Colombia -en las décadas del 80 y 90-. O sea, los que afirman esta

\footnotetext{
18 Apodado "el Esteban", tiene 38 años y es el líder de la banda "Los Rosarinos". Cayó preso en 2012 acusado de robar autos de alta gama en Buenos Aires y desguazarlos en Rosario. También se lo vincula con el narcotráfico. Información disponible en: http://www.perfil.com/sociedad/revelan-nombres-y-datos-del-nuevo-mapa-narcode-rosario-0078.phtml. Fecha de consulta: 29/06/16.

${ }^{19}$ Entrevista realizada en Mayo de 2016.

${ }^{20}$ Se refiere al cobro de dinero por circular al interior de un territorio determinado.

21 "La narcofamilia: fabricaban media tonelada de droga por mes en un country". La Nación, 20/10/13. Disponible en: http://www.lanacion.com.ar/1630707-la-narcofamilia-fabricaban-media-tonelada-de-droga-por-mes-en-uncountry. Fecha de consulta: 02/04/16.

${ }^{22}$ Cocaína de alta pureza dedicada a sectores de alto poder adquisitivo.

${ }^{23}$ Refiere al intento de ingresar a Portugal un cargamento con 1200 kilos de cocaína escondidos en tambores de pulpa de fruta congelada. Más información en: https://www.fiscales.gob.ar/narcocriminalidad/peras-blancascondenaron-a-9-y-12-anos-de-prision-a-los-cuatro-acusados/. Fecha de consulta: 05/05/2016.

24 Causa vinculada al contrabando de cocaína a Europa. Más información en: http://www.lanacion.com.ar/1901462-caso-carbon-blanco-el-juicio-por-lavado-de-dinero-sera-en-agosto.

${ }^{25}$ Entrevista realizada en mayo de 2016.
} 
situación ${ }^{26}$ intentan asemejar las organizaciones clandestinas de la ciudad de Rosario con los cárteles de fama mundial.

Las alusiones mediáticas a las que referimos cobran relevancia a partir del rol que "los medios" jugaron a la hora de contribuir a instalar en la agenda pública la problemática del narcotráfico, con "Los Monos" como principal exponente. Al respecto, en febrero de 2014, uno de los diarios nacionales de mayor difusión -Claríntitulaba "Droga y crímenes mafiosos: la historia de 'Los Monos '; la banda que aterroriza a Rosario"27. La nota señala a la banda liderada por el clan Cantero como "el principal grupo narco de la ciudad" con ganancias de $\$ 100.000$ diarios. Anteriormente hemos referido a la diferenciación entre narcomenudeo y el negocio de exportaciónimportación de drogas ilícitas, donde la mayor parte de las ganancias del mercado queda en este último sector, con lo cual la caracterización de "principal grupo narco" amerita una mirada más compleja. Sin embargo, el interés en citar esta nota -entre otras $^{28}$ - radica en la incidencia sobre la conformación de la agenda pública a partir de la caracterización de una ciudad "aterrorizada" por una "banda narco".

Estas caracterizaciones no son propiedad exclusiva de medios de comunicación nacionales. Una periodista de policiales [P2] entrevistada realizó una lectura del rol de los medios de comunicación locales de mayor masividad: "existe una serie de circunstancias que se fueron tapando gracias a lo que fue una venta excesiva de lo que era la banda 'Los Monos' como el eje del mal y es que tenían determinadas características como para presentarse como el eje del mal: eran los negros desdentados del barrio La Granada que tenían plata y eso a la gente le molestaba. Yo no creo que lo que se repudie sea el narcotráfico. Lo que [la población] repudia es que los negros tengan plata, eso molesta en cualquier lugar, hasta con los narcos... Y esa historia de mostrar las cosas que tenían, o sea, lo que habían podido comprar desde una villa, cuando muchos de ellos hace tiempo que no vivían en una villa, generó todo este morbo, que había que explotarlo a full. Hay un relato en el cual en La Capital tenés uno de los principales pilares" ${ }^{29}$.

\footnotetext{
${ }^{26}$ Principalmente medios de comunicación, en la Introducción citamos el informe del programa Periodismo Para Todos, de Canal 13 de Buenos Aires y en la misma sintonía fueron las coberturas de algunos medios locales, principalmente Canal 3 y La Capital, como así también la nota del diario Clarín titulada "La banda de Los Monos, la banda que aterroriza a Rosario" comentada en el presente capítulo.

27 "Droga y crímenes mafiosos: la historia de 'Los Monos ', la banda que aterroriza Rosario". Clarín, 23/02/14. Disponible en http://www.clarin.com/policiales/historia-Monos-banda-aterroriza-Rosario_0_1090091141.html. 28 "Autos de lujo y una mansión de tres hectáreas, entre los bienes que le quieren sacar a "Los Monos". Clarín, 18/02/16. Disponible en: http://www.clarin.com/policiales/autos-mansion-hectareas-quierenmonos_0_V18ow6Rqx.html.

http://www.clarin.com/policiales/narcotrafico-los_monos-pacto-cantero_0_ByznjoYvXl.html.

${ }^{29}$ Entrevista realizada en mayo de 2016.
} 


\section{Actores, disputas y "cocinas". Una breve crónica}

La cronología de homicidios vinculados a las disputas de "Los Monos" comienza con el asesinato de Martin "Fantasma" Paz, el 8 de septiembre de 2012. El joven de 27 años era cuñado del "Pájaro" Cantero, el jefe de la banda "Los Monos". Luego, la madrugada del 26 de mayo de 2013, en la puerta del boliche bailable "Infinity Night", en la vecina ciudad de Villa Gobernador Gálvez, el líder de “Los Monos” recibió un ataque que terminó con su vida ${ }^{30}$.

Este hecho desató una serie de asesinatos y hechos violentos, comenzando por el homicidio del dueño del local bailable donde fue asesinado "Pájaro" Cantero ${ }^{31}$. Luis "Pollo" Bassi ${ }^{32}$ fue el primer señalado como responsable intelectual del crimen. Luego del homicidio de "Pájaro" Cantero, comenzó una serie de presuntos ajustes de cuentas en los que resultaron muertos los dos hermanos del "Pollo" Bassi, Leonardo y Maximiliano $^{33}$, y su padre Luis ${ }^{34}$. Todos fueron ejecutados a balazos en diferentes atentados entre fines de 2013 y octubre del año siguiente en la puerta de la remisería que la familia Bassi poseía en Villa Gobernador Gálvez.

El homicidio de Martin "Fantasma" Paz -ocurrido en 27 de febrero y Entre Ríos-, como así también el de Maximiliano “Quemadito” Rodríguez ${ }^{35}$-en la intersección de calle Corrientes y Avenida Pellegrini- generaron una conmoción importante debido a la ubicación céntrica donde se produjeron los hechos.

Retomando las caracterizaciones mediáticas del homicidio de Claudio "Pájaro" Cantero y las culpabilidades señaladas, a diferencia de la hipótesis del diario La Capital señalando la existencia de una disputa entre el sector ligado a Luis "Pollo” Bassi y el clan Cantero,

30 “Asesinaron de seis balazos al Pájaro Cantero, líder de Los Monos”. La Capital, 27/05/13. Disponible en: http://www.lacapital.com.ar/asesinaron-seis-balazos-al-pajaro-cantero-lider-los-monos-n419297.html. Fecha de consulta: 01/06/16.

31 "Crimen del Pájaro Cantero ya tuvo una fatal secuela". El Ciudadano, 28/05/13. Disponible en: http://www.elciudadanoweb.com/acribillan-a-dueno-del-boliche-donde-mataron-al-pajaro/. Fecha de consulta: 30/05/16.

32 Luis Orlando "El Pollo" Bassi, oriundo de la localidad de Villa Gobernador Gálvez, señalado en las diversas entrevistas como un actor importante del narcomenudeo en dicha ciudad.

33 “Asesinaron a balazos a otro hermano del Pollo Luis Bassi en Villa Gobernador Gálvez". La Capital, 12/02/14. Disponible en: http://www.lacapital.com.ar/policiales/asesinaron-balazos-otro-hermano-del-pollo-luis-bassivilla-gobernador-galvez-n459843.html. Fecha de consulta: 05/09/16.

34 “Tras ser atacado a balazos, murió el padre de un presunto narco rosarino". La Nación, 22/10/14. Disponible en: http://www.lanacion.com.ar/1737655-ataque-con-sello-narco-acribillaron-al-padre-de-luis-pollo-bassi. Fecha de consulta: 05/09/16.

35 "Piden 17 años de prisión al acusado de asesinar al "Quemadito" Rodríguez". La Nación, 24/08/16. Disponible en: http://www.lacapital.com.ar/policiales/piden-17-anos-prision-al-acusado-asesinar-al-quemadito-rodriguezn1213923.html. Fecha de consulta: 13/02/17. 
la crónica de revista Anfibia apunta que un investigador de la ciudad afirmaba que se llevó a cabo una guerra entre importadores de cocaína -Paz e Isabel "Reina" Quevedoy los dueños del territorio -principalmente "Los Monos"-. Señalan allí que se suscitó una disputa por el excedente, que comenzaba a ser más grande a partir de la existencia de "cocinas" de clorhidrato de cocaína ${ }^{36}$. Dicha disputa generó el asesinato de Martin "Fantasma" Paz en 2012 y los homicidios posteriores, principalmente el de Claudio "Pájaro" Cantero.

Al ser consultado por las disputas violentas de 2012 y 2013, uno de los periodistas de policiales [P1] señalaba la modificación que forjó el asentamiento de "cocinas" de pasta base a partir de generar un excedente mucho mayor a las ganancias que el narcomenudeo dejaba hasta el momento. Ello generó disputas entre los actores por apropiarse de las crecientes ganancias: "vos al cocinar generás un excedente que es propio, y ese es un fenómeno que se produce al menos una década atrás. Los grupos delictivos de acá comienzan a cocinar y comienza a haber un excedente fenomenal en el marco también de una explosión del consumo de drogas. Y el tema del excedente es el que termina explicando también la última guerra narco de los últimos cuatro o cinco años, o sea el que tiene las cocinas tiene el excedente y al "Fantasma" Paz todo indica que lo matan justamente por estar cocinando por cuenta propia más allá de que pudo haber mejicaneado algo ahí. Entonces los sectores importadores [Paz], no exportadores, terminan enfrentados a tiros, apoyados en gente de territorio, como la gente de Bassi en Villa Gobernador Gálvez y algunos aliados en zona Sur, frente a 'Los Monos ', dueños del territorio.

Al consultar por los actores que participaban de los últimos enfrentamientos, el entrevistado señala: "Por un lado 'Reina 'Quevedo y el padre del 'Fantasma 'Paz y por otro los dueños del territorio, o sea 'Los Monos ', que, en un momento, a partir del 'Fantasma ', eran como todos socios de un mismo negocio" ${ }^{\prime 3}$.

Como hemos visto, los relatos de algunos de los entrevistados dan cuenta de una disputa que antes que darse entre "Los Monos" y "los Bassi" -cómo mediáticamente se enfatizó-, sería entre los dueños de territorio -"Los Monos" - y los importadores -Paz, "Reina" Quevedo-.

La serie de homicidios que se desató -especialmente luego del crimen de Claudio "Pájaro" Cantero- son en buena medida resultado de un negocio que generaba márgenes de ganancia desconocidos hasta el momento. Ello no debe perder de vista el

36 “Los Monos ! historia de un clan”. Revista Anfibia. Disponible en: http://www.revistaanfibia.com/cronica/los-monos-historia-de-un-clan/. Fecha de consulta: 05/02/16.

${ }^{37}$ Entrevista realizada en mayo de 2016. 
reparo a la hora de asociar la creciente tasa de homicidios con el narcotráfico. Atribuir única o principalmente a este fenómeno el crecimiento de la violencia encapsulada en ciertos barrios es una simplificación.

Si bien la presencia de grupos dedicados al narcomenudeo desempeña un papel en el aumento de estos crímenes, son centrales otros factores habitualmente relegados. Entre ellos las relaciones cotidianas violentas entre jóvenes, la gran circulación de armas (al respecto observamos que durante el 2014 se realizaron 560 denuncias por robo o extravío de armas de fuego en toda la provincia, de las cuales 110 pertenecían a policías santafesinos $)^{38}$.

En función de los testimonios relevados, el relato de la trayectoria de "Los Monos" creemos que puede asemejarse a la situación descripta por el especialista Juan Garzón Vergara -citado por el informe de CELS de 2016-, quien señala que en América Latina las organizaciones criminales "funcionan con una lógica de micro red predatoria, como grupos de individuos que trabajan juntos en un territorio determinado para explotar a otros en beneficio propio, toman provecho de la informalidad y el mercado negro recurriendo tanto a mercados legales como ilegales" (CELS, 2016:97).

Los relatos recabados en las entrevistas realizadas -sumados a lecturas de fuentes secundarias- nos llevan a situar a "Los Monos" entre los actores del narcomenudeo. El análisis del caso "Los Monos" da cuenta de una situación en la que la agenda pública, teñida por un fuerte impulso mediático, conformó al narcotráfico como una cuestión merecedora de interés por parte de las autoridades gubernamentales, presentándola como causa fundamental de problemáticas como la seguridad y la violencia urbana. Ello condicionó al menos algunas de las problematizaciones e intervenciones del MS en relación al narcomenudeo.

\section{Del delito federal al "combate al narcotráfico." Ministerio de Seguridad y narcomenudeo}

El apartado que aquí comienza tiene por objetivo analizar el modo en que el MS problematizó e incorporó en la agenda gubernamental la cuestión narcotráfico. Tal como sostuvimos en el apartado destinado a la metodología, la relevancia que encuentran las entrevistas en profundidad realizadas a informantes claves como fuente primaria de

\footnotetext{
${ }^{38}$ Nota de Rosario 12 "La policía "perdió" 100 armas en un año. Publicada 18 de Enero de 2015. Disponible en línea: https://www.pagina12.com.ar/diario/suplementos/rosario/10-47581-2015-01-18.html Fecha de consulta: Septiembre de 2016.
} 
información, dan cuenta de la esencia exploratoria del presente trabajo e intentan suplir la escasez de fuentes secundarias. Al respecto, para producir información, realizamos entrevistas semi-abiertas a informantes claves, con conocimiento respecto del desenvolvimiento del MS y la PSF frente al fenómeno del narcomenudeo en la ciudad de Rosario.

En el caso del MS se intentó entrevistar a Raúl Lamberto, quien se desempeñara como Ministro de Seguridad de la Provincia de Santa Fe en el período estudiado. Lamentablemente, luego de reiteradas oportunidades en que la entrevista fuera postergada, se hizo imposible llevarla a cabo, una vez que el potencial entrevistado asumió su nuevo rol al frente de la Defensoría del Pueblo. En el caso del análisis del desenvolvimiento del MS y de la caracterización que dicha agencia tuvo del fenómeno narcomenudeo en el período estudiado, se suplió la ausencia de entrevistas con el relevamiento de notas y testimonios recabadas en diferentes medios de comunicación, recortes periodísticos y análisis del denominado "Plan de Seguridad Democrática ${ }^{39}$ ", de modo que permitan analizar el posicionamiento público de los protagonistas, la problematización que dicha agencia realizó sobre la cuestión y las principales intervenciones. Se han analizado los posicionamientos del por entonces Ministro Lamberto, el Secretario de Seguridad Comunitaria, Ángel Ruani y el Secretario de Seguridad Pública de dicho Ministerio, Matías Drivet.

Un exhaustivo repaso de los posicionamientos públicos realizados por las autoridades del MS a partir del año 2012, sumado a la lectura recabada en entrevistas a otros actores claves del caso "Los Monos", nos permite observar la existencia de dos momentos respecto a la problemática en cuestión.

En primera instancia la postura del MS estuvo atravesada por destacar el carácter federal del delito y resaltar la competencia de las esferas nacionales del Poder Ejecutivo y el Poder Judicial. Luego de la persistencia del tema en la agenda pública vemos aparecer un segundo momento caracterizado como "combate al narcotráfico" cuyo principal rasgo pasó por el derribo de bunkers y el impulso de la causa judicial llevada adelante el juez Juan Carlos Vienna por el asesinato de Martin "Fantasma" Paz. En este sentido observaremos cómo la persistencia del tema en agenda pública y la coyuntura crítica ejercieron cierta influencia en el modo en que el MS incorporó a la agenda gubernamental la problemática.

\footnotetext{
${ }^{39}$ El Plan de Seguridad Democrática fue elaborado por el Poder Ejecutivo de la Provincia en Octubre de 2012. Contemplaba un incremento de recursos económicos y humanos destinados a seguridad, durante 18 meses. A su vez contemplaba una reestructuración de la fuerza policial, sobre ello volveremos en los capítulos siguientes.
} 
En un primer momento los tomadores de decisiones del gobierno del FPCyS sostuvieron que el narcotráfico era un delito federal, y por ende era de competencia del Poder Judicial Federal y el Poder Ejecutivo Nacional, a través del control de las fronteras y control del espacio aéreo. Así, por ejemplo, el Secretario de Seguridad Pública, Matías Drivet, señalaba que "sin control del espacio aéreo no vamos a tener control sobre el narcotráfico", destacando que el mismo es "un delito federal" y que el rol de las brigadas de la PSF al respecto será "en todo caso acompañar y complementar el trabajo federal" ${ }^{\prime 0}$.

La competencia federal respecto al narcotráfico aparece destacada en numerosas declaraciones públicas vertidas a lo largo del año 2012, tanto por Raúl Lamberto ${ }^{41}$ como por el mismo Gobernador Antonio Bonfatti ${ }^{42}$.

Se observa un cambio de posicionamiento a partir de la persistencia en la agenda pública de la problemática del narcotráfico como un asunto merecedor de atención por parte de las autoridades provinciales. Ello condujo a que las mismas tomaran cartas en el asunto incorporando en la agenda gubernamental la cuestión narcotráfico en términos de "combate al narcotráfico".

Cobb y Elder (1983) definen las condiciones necesarias y suficientes para que un tema o un problema sean incluidos en una agenda gubernamental. Al respecto señalan que "el tema o el problema debe ser competencia de las autoridades públicas en general, o de una autoridad pública particular. La competencia no debe ser aquí interpretada en su sentido puramente jurídico o institucional, sino en una perspectiva más amplia. No es entonces la pertinencia jurídica o institucional la que determinará el ingreso a la agenda gubernamental de la temática narcotráfico, sino el hecho de que "a los ojos de los miembros de la comunidad la acción sea competencia de alguna entidad gubernamental" (Cobb y Elder, 1983:115).

\footnotetext{
${ }^{40}$ Declaraciones del Secretario de Seguridad Pública en el programa de televisión Los Olvidados, diciembre de 2012. Disponible en: https://www.youtube.com/watch?v=Qpuf5an-dUU. Fecha de consulta 02/05/16.

41 La Capital, 03/09/12. Disponible en http://www.lacapital.com.ar/lamberto-el-narcotrafico-es-un-delitofederal-donde-somos-una-fuerza-colaboracion-n359425.html. Asimismo, http://www.lacapital.com.ar/unpedido-descomprimir-el-escandalo-n536018.html. Portal de noticias de Santa Fe "El consultor Web": 24 de Octubre de 2012 http://www.elconsultorweb.com/asumieron_nuevas_autoridades_en_el_ministerio_de_seguridad/68472.html. 42 La Capital, 27 de Enero de 2013 (http://www.lacapital.com.ar/bonfatti-el-narcotrafico-es-un-delito-y-unaresponsabilidad-que-compete-todos-n425834.html). Portal de noticias “Ambito.com": 12/11/12 (http://www.ambito.com/662905-bonfatti-volvio-a-culpar-a-garre-por-el-narcotrafico-en-la-provincia-desanta-fe). El Ciudadano, 30/01/13 (http://www.elciudadanoweb.com/bonfatti-y-binner-denunciaron-unaembestida-politica-de-la-rosada/)
} 
En otras palabras, el MS progresivamente fue abandonando -por ineficaz- el argumento anclado en el carácter federal del narcotráfico para dar lugar a otro tipo de intervenciones, pretendidamente más activas para el tratamiento de la cuestión.

El discurso del MS anclado en una impronta democrática y participativa de la seguridad, con control civil sobre la PSF y la creación de policías de proximidad, puede enmarcarse en la propuesta de adaptación de Garland (vale recordar, el Estado acepta la dificultad de abordar las múltiples dimensiones del delito). La misma se irá alternando con políticas de seguridad de "combate al narcotráfico" que pretenden restaurar el mito del Estado soberano con capacidad de garantizar el orden y la seguridad.

Al respecto, el juez provincial que actuó en una de las causas emblemáticas a "Los Monos" señalaba en la entrevista realizada lo siguiente:

"E: Recién usted relataba cómo el homicidio de Cantero despertó la alarma del Ministerio de Seguridad

Rta: Claro, despierta el poder político porque dice `esto pone en juego nuestra credibilidad '... Se vinieron a sentar conmigo, y les dije 'bueno, pero esto que yo tengo acá, que son las investigaciones previas, todavía estaba todo atado con alambre, atado con alambre me refiero que todavía no estaba todo armado como para cerrarlo... Y ahí nos decidimos a dar un golpe, digamos, a hacer un allanamiento". 43

El entrevistado se refiere a los allanamientos realizados de manera conjunta en propiedades del clan Cantero, de las cuales participaron el Gobernador Bonfatti, el Ministro de Seguridad Lamberto, el fiscal Guillermo Camporini y el juez Juan Carlos Vienna ${ }^{44}$.

A partir de la situación "iniciadora" relacionada con los homicidios desatados luego del asesinato de Claudio "Pájaro" Cantero, el MS define la cuestión narcotráfico en términos de "combate contra el narcotráfico", incorporándola simultáneamente en su agenda de gobierno. Este viraje, motivado por la conveniencia de exhibir un rol más activo en función de la urgencia de la coyuntura, tuvo dos arietes. Por un lado, el impulso de la causa judicial encabezada por el juez Juan Carlos Vienna y por otro, una política de derrumbe de puesto de ventas de drogas ilícitas, los denominados bunkers.

En una entrevista televisiva con Alejandro Grandinetti en julio de 2013, Raúl Lamberto -luego de ser consultado por la colaboración en dicha causa- sostenía:

\footnotetext{
${ }^{43}$ Entrevista realizada en Julio de 2016.

${ }^{44}$ Se pueden observar imágenes de los allanamientos conjuntos en la cobertura de los diarios. Por ejemplo, Página/12, 15/06/13. Disponible en: https://www.pagina12.com.ar/diario/suplementos/rosario/9-39320-201306-15.html
} 
"Tenemos que trabajar en conjunto con los fiscales, con los equipos que ha dispuesto la Corte y el propio MS, para que trabajen sobre toda la actividad probatoria. Estamos en este camino. Creo que es un hecho muy importante, le diría muy emblemático, porque acá estábamos sobre temas de una alta violencia con muchos muertos, gente herida, barrios afectados, lo cual traía consecuencias que cada día iban creciendo. Entonces esta decisión muy fuerte, primero de un juez, que es el Doctor Vienna, de un procurador de la Corte, que es el Doctor Barraguirre, de los fiscales que intervienen, y por supuesto del Ministerio de Seguridad y de la Policía de la Provincia, en particular una decisión que toma el jefe de la Policía que es designar un grupo de investigadores para que tomen el tema [para su seguimiento]. Esto ha permitido resultados muy importantes. Todavía queda muchísimo [por hacer]. Y sí, yo creo que sí, que se trata de una de las causas más importantes que hay en el país" ${ }^{45}$.

El periodista entrevistado [P1], dio su parecer respecto a la actuación conjunta entre el MS y el Poder Judicial provincial en torno al caso "Los Monos":

"Fue evidente que hubo una puesta en escena política, como respuesta a lo que significó el encarcelamiento de Tognoli, en medio de la lucha entre socialistas y kirchneristas, Nación-Provincia. Lo que tuvieron a mano, en la desesperación, después del crimen del 'Pájaro 'Cantero, fue esta investigación incipiente -que apenas llevaba poco más de un mes- basada en escuchas, más allá que la labor de inteligencia de ellos fuera la misma que podría hacer cualquiera. Implicó una ofensiva que se hizo a los ponchazos, con una investigación que en sede federal tardaría un año. Acá una investigación de un mes dejó abierto un montón de flancos, en medio también de una disputa, no solo de kirchnerismo contra socialismo, sino de la justicia federal contra la justicia provincial, y cada uno alineado en diferentes lugares. Y la cuestión de la competencia se termino a merced de un acuerdo que el fiscal de casación, inesperadamente para todo el mundo, termina desistiendo de reclamar esa competencia producto de un acuerdo político".

El contexto de situación crítica en materia de seguridad generó una fuerte presión desde la agenda pública demandando la intervención gubernamental. El posterior proceso decisional llevado adelante por el MS estuvo caracterizado por dicha urgencia. La problematización, puesta en agenda gubernamental y toma de decisión en términos de "combate al narcotráfico" estuvo regida por esta coyuntura crítica y conllevó un proceso decisorio cambiante, orientado por la necesidad de mostrar resultados positivos a la ciudadanía. En términos de Garland, este viraje implicó un reforzamiento de las posturas de "negación histérica y reactivación del viejo mito del Estado

\footnotetext{
${ }^{45}$ Entrevista realizada en el año 2013. Disponible en línea: https://www.youtube.com/watch?v=4Iq-0R6WHLE.
} 
soberano", focalizadas en mayor castigo expresivo, autoritario y represivo. Advierte Garland que "al mismo tiempo que la 'máquina administrativa' del Estado ha tratado de adaptarse a sus límites y terminar con las realidades que le generaban malestar, el 'brazo político' del Estado se ha comprometido frecuentemente con una forma de 'negación' que se manifiesta cada vez más histérica” (Garland, 1997:103). Se trata en este caso de intentos de evadir el dilema, "particularmente por parte de los funcionarios electos, que juegan cada vez más un papel importante en el diseño de las políticas de control del delito" (Garland, 1997:189). El viraje a partir de la coyuntura crítica y la presión de la agenda pública, llevó a que las políticas de seguridad se enfoquen en mostrarse "duros contra el delito" a partir de trasmitir a la sociedad que algo se está haciendo en relación a ese delito, en este caso el narcomenudeo.

Podría aventurarse inclusive que el MS se montó sobre el tratamiento mediático de la cuestión narcotráfico sin cuestionarlo, aceptando ese "otro" que los mismos medios presentaban como responsable/culpable de la crítica situación social.

Este nuevo posicionamiento del MS se realizó siguiendo en parte caracterizaciones que hicieron los medios masivos de comunicación en las que se presentaba al clan Cantero y a los "soldaditos" como figuras paradigmáticas del narcotráfico.

La problematización alrededor de la cuestión del narcotráfico realizada por el MS no logró (o no se propuso) diferenciar entre actores de narcotráfico, dedicados a la importación-exportación del comercio de drogas ilegales; y actores del narcomenudeo. Las intervenciones concretas realizadas en lo que -siguiendo al informe de Font, Cozzi, Marasca y Mistura (2014) - se denominó "desfederalización ad hoc", tenían como principales objetivos los eslabones inferiores del narcomenudeo. A nuestro entender, este modo de intervenir dio cuenta nuevamente del carácter contingente que anteriormente atribuíamos al proceso de toma de decisiones encabezado por el MS.

La urgencia por intervenir rápidamente ante la "presión" proveniente de la agenda pública y la necesidad de presentar resultados en materia de la "cuestión narco", tuvo como consecuencia perseguir a los eslabones del narcomenudeo. Como hemos señalado, no se percibe que se haya realizado una distinción entre lo que aquí denominamos narcomenudeo y el fenómeno del narcotráfico.

La estrategia de "combate al narcotráfico" permitió mostrar acciones -el derrumbe de bunkers, operativos en conjunto con sectores del Poder Judicial de la provincia- en relación con el delito, ello emergió como un "acting" en términos de Garland. Frente a las presiones provenientes de los medios de comunicación y la 
indignación social se ensayó "un espectáculo de fuerza punitiva contra ciertos individuos, utilizado para reprimir cualquier tipo de reconocimiento de la incapacidad del Estado para controlar el delito en niveles aceptables" (Garland, 2005:226).

\section{Reflexiones finales}

La forma en que desde el MS se problematizó al narcomenudeo como "combate al narcotráfico" expresó la necesidad de mostrar efectividad frente a la sociedad, evidenciando la ambivalencia de las políticas de seguridad anteriormente señalada.

La construcción de un otro (elaborada en la agenda pública) fácilmente caracterizable como peligroso o amenazante para la sociedad, se reflejó en la problematización del MS. La política de control del delito se enfoca así en una población impopular. Se observa, entonces que, en la agenda gubernamental se filtra la problemática presente en la agenda publica, se la traduce a fines de hacerla "intervenible". Por ello sostenemos que la formulación de la política pública en relación al narcomenudeo se sirvió de la versión predominante en agenda pública.

Nos permitimos ir un poco más allá en esta caracterización. Observamos en una nota en la revista Panamá ${ }^{46}$ como Juan Carlos Torre realiza un pormenorizado análisis en relación los efectos del 2001 sobre el peronismo, tema que en apariencia tiene muy poco que ver con las líneas esgrimidas en esta tesina. Sin embargo, retomamos cierta caracterización allí leída: “...como nos lo cuentan los testimonios de antropólogos y periodistas, en los barrios de las clases medias bajas es muy difundida la visión de los pobres como "vagos" que "viven del estado" y cuya presencia muy cercana es una fuente de inseguridad" (Torre, 2017:2). La problematización que el MS realizó a la hora formular la política pública en relación al narcomenudeo guarda cierta relación con aquella caracterización señalada por Juan Carlos Torre.

Creemos que a la hora de problematizar la incorporación en agenda gubernamental para la formulación de la política pública alrededor del narcomenudeo el factor comunicacional jugó un rol fundamental, la necesidad de mostrar que "algo se está haciendo" al respecto, sirviéndose de perseguir a la figura de "narco" previamente constituida en agenda pública fue uno de los aspectos cruciales en la formulación elaborada por el MS.

Por último, sostenemos que formular políticas públicas en materia de drogas ilícitas debe tener como punto de partida la comprensión de que el narcotráfico es una

\footnotetext{
${ }^{46}$ Conferencia en el Congreso de Ciencia Política 2 agosto 2017. Publicada en Revista Panama. Disponible en línea en: http://panamarevista.com/los-huerfanos-de-la-politica-de-partidos-revisited/
} 
economía con demanda inelástica. Ello implica que por mucho que se combata la oferta de drogas ilícitas, se sostiene la demanda. Con esto intentamos realizar un llamado de atención sobre los efectos del prohibicionismo, los que generan un aumento de la violencia sin lograr disminuir el comercio. A nuestro entender los decisores estatales precisan incorporar esta premisa presente en propuestas como la de Damián Zaitch, quien sostiene que se puede aplicar una política de reducción de daños, no solo en relación al consumo de drogas ilícitas, sino también a la hora de formular políticas públicas en relación al comercio de drogas ilícitas.

\section{Bibliografía}

-BERGMAN, M. (2016). Drogas, narcotráfico y poder en America Latina. Buenos Aires: Fondo de Cultura Economica.

-Centro de Estudios Legales y Sociales (2016). Derechos humanos en la Argentina. Informe 2016. Buenos Aires.

-COZZI, E. (2014 ). “Los tiratiros”, en Estudios, No 32, pp. 265-284. -COZZI, E., Font, E., y Mistura, M. E. (2014). “Desprotegidos y sobrecriminalizados: interacciones entre jóvenes de sectores populares, policía provincial y una fuerza de seguridad nacional en un barrio de la ciudad de Rosario", en Revista Derechos Humanos, No 8. Buenos Aires: Infojus.

-DALLOSO, N. (2012). La compleja relación entre el poder político y las fuerzas de seguridad.

- EMMERICH, N. (2009). "Políticas de seguridad y lucha contra el narcotráfico en la ciudad de Buenos Aires”. Coloquio Internacional: América Latina. Gobierno. Diseño institucional y politicas públicas en ciudades capitales. Buenos Aires.

- EMMERICH, N., \& RUBIO, J. (2014). Narcos, políticos y medios de comunicación en Rosario,

República Argentina. Documentos de Trabajo. Universidad de Belgrano. Ciudad autonoma de Buenos Aires, 3-16.

-EVENTON, R. (2013). Haciendo la vista gorda. Corrupción y violencia relacionada con las drogas en Rosario. Transnational Institute (TNI). Serie mercados de drogas y violencia No.1.

-FONT, E. (1999). Transformaciones en el gobierno de la seguridad: análisis exploratorio de conceptos y tendencias. En M. Sozzo, Seguridad Urbana. Nuevos problemas, nuevas perspectivas. Santa Fe: UNL (Universidad del Litoral).

-GARLAND, D. (2005) La cultura del control. Barcelona: Gedisa 
-GARZÓN, J. C. (2015). Reprimir o regular: el falso dilema de las políticas de drogas. Bogotá: Friedrich Ebert Stiftung.

-Ministerio Público de Acusación. (2014). Informe de Homicidios 2014. Resumen ejecutivo. Rosario.

- MISTURA, M. E., FONT, E., COZZI, E., \& MARASCA, M. (2014). "Retórica democrática y business as usual. Avances y retrocesos en el gobierno de la seguridad en Santa Fe desde la creación del Ministerio de Seguridad a la ‘intervención 'federal en Rosario". VII Seminario Internacional Políticas de la Memoria. Presente y Tradición del Pensamiento Emancipatorio. Centro Cultural De La Memoria Haroldo Conti, Secretaria de Derechos Humanos, Ministerio De Justicia y Derechos Humanos de la Nación. Buenos Aires.

-ROSSI, A. (2014). Narcotráfico y seguridad en America Latina. Revista de la Bolsa de Comercio de Rosario.

-RUGGIERO, V. (1999). Delitos de los débiles y de los poderosos: ejercicios de anticriminologia. Buenos Aires: Ad-Hoc.

-YOUNG, J. (2003). "Merton con energía, Katz con estructura. La sociología del revanchismo y la criminología de la transgresión". Delito y Sociedad.

-ZAMUDIO ANGLES, C. (2013). Jóvenes en el narcomenudeo: el caso Ciudad de México. Revista Latinoamericana de Seguridad Ciudadana(13), 111-123. 